\title{
Bone metastasis pattern in initial metastatic breast cancer: a population-based study
}

This article was published in the following Dove Press journal:

Cancer Management and Research

\author{
Zhenchong Xiong ${ }^{1-3, *}$ \\ Guangzheng Deng ${ }^{1-3, *}$ \\ Xinjian Huang ${ }^{1-3, *}$ \\ Xing $\mathrm{Li}^{1-3}$ \\ Xinhua $\mathrm{Xie}^{1-3}$ \\ Jin Wang ${ }^{1-3}$ \\ Zeyu Shuang ${ }^{1-3}$ \\ Xi Wang ${ }^{1-3}$
}

'Department of Breast Surgery, Sun Yat-sen University Cancer Center, Guangzhou, China; ${ }^{2}$ State Key Laboratory of Oncology in Southern China, Guangzhou, China; ${ }^{3}$ Collaborative Innovation Center for Cancer Medicine, Guangzhou, China

*These authors contributed equally to this work
Correspondence: Xi Wang

Sun Yat-sen University Cancer Center,

65I Dongfeng Road East, Guangzhou

510060 , China

Tel +86 I 3609648985

Email wangxi@sysucc.org.cn
Purpose: Bone is one of the most common sites of breast cancer metastasis, and population-based studies of patients with bone metastasis in initial metastatic breast cancer (MBC) are lacking.

Materials and methods: From 2010 to 2013, 245,707 breast cancer patients and 8901 patients diagnosed with initial bone metastasis were identified by Surveillance, Epidemiology, and End Results database of the National Cancer Institute. Multivariate logistic and Cox regression were used to identify predictive factors for the presence of bone metastasis and prognosis factors. Kaplan-Meier method and log-rank test were used for survival analysis.

Results: Eight thousand nine hundred one patients with initial MBC had bone involvement, accounting for $3.6 \%$ of the entire cohort and $62.5 \%$ of the patients with initial MBC. Also, $70.5 \%$ of patients with bone metastasis were hormone receptor (HR) positive (HR+/human epidermal growth factor receptor 2 [HER2]-: 57.6\%; HR+/HER2+: 12.9\%). Patients with initial bone metastasis had a better 5-year survival rate compared to those with initial brain, liver, or lung metastasis. HR+/HER2- and HR+/HER2+ breast cancer had a propensity of bone metastasis in the entire cohort and were correlated with better prognosis in patients with initial bone metastasis. Local surgery had significantly improved overall survival in initial MBC patients with bone metastasis.

Conclusion: Our study has provided population-based estimates of epidemiologic characteristics and prognosis in patients with bone metastasis at the time of breast cancer diagnosis. These findings would lend support to optimal surveillance and treatment of bone metastasis in breast cancer. Keywords: initial metastatic breast cancer, bone, molecular subtype, survival

\section{Introduction}

Bone is one of the most common sites in patients with metastatic breast cancer (MBC) as $60 \%-75 \%$ of MBCs are firstly diagnosed with bone metastasis. ${ }^{1-3}$ Severe osteodynia, pathologic fractures, and nerve compression are the three most common symptoms of bone metastasis and are associated with poorer outcome and reduced life quality. However, there still remains a large proportion of patients who have no clinical symptom and miss detection of bone metastasis at the diagnosis of breast cancer. ${ }^{4-6}$ As most studies of bone metastasis are based on data from relapsed breast cancer, population-based studies relating to prevalence pattern and survival of patients with bone metastasis in initial MBC are still rare.

Breast cancer is a heterogeneous disease in which the biologic behavior of cancer cells and the outcomes of breast cancer patients greatly vary among different molecular subtypes (luminal A, luminal B, human epidermal growth factor 
receptor 2 [HER2]-enriched, basal-like) based on the status of estrogen receptor (ER), progesterone receptor (PR), and HER2 ${ }^{7,8}$ Studies have shown that the risk of bone metastasis is subtype dependent in breast cancer. ${ }^{9,10}$ Luminal A breast cancer with positive expression of ER/PR was reported to have a higher propensity to develop bone metastasis. ${ }^{11}$ With the assessment of the gene expression of the primary tumor, studies reported that over $60 \%$ of primary tumors, which subsequently developed bone metastasis, were ER-positive/ PR-positive breast cancer. ${ }^{12}$ Delpech et al further showed that the risk of bone metastasis in patients with hormone receptor (HR)-positive breast cancer was 1.66 times higher than the risk of patients with HR-negative breast cancers by developing a bone metastasis prediction model. ${ }^{13}$ With regard to HER2-enriched subtype, women with HER2enriched cancer were less likely to have bone metastasis, compared to those with HER2-negative breast cancer. ${ }^{14}$ Although the risk of bone metastasis is different among diverse molecular subtypes of breast cancer, integration of these genes for the prediction of bone metastasis is seldom reported and outcomes among different molecular subtypes remain unclear in initial $\mathrm{MBC}$ with bone metastasis.

The purpose of our study is to use the Surveillance, Epidemiology, and End Results (SEER) database to assess the incidence of bone metastasis in initial MBC and to characterize patients with bone metastasis in initial MBC. Further, we would provide survival estimate and identify the prognostic factors for patients who have developed bone metastasis at the time of breast cancer diagnosis.

\section{Materials and methods}

The SEER database including 18 registries accounts for $30 \%$ of the US population. ${ }^{15}$ We searched patients with invasive breast cancer between January 2010 and December 2013. Patients with only a death certificate or autopsy, as well as those with incomplete follow-up were not included in our study. Then, we excluded patients with unknown age or younger than 18; thus, 245,707 patients were included in our study. Among these, 14,246 patients were diagnosed with initial MBC and 8901 patients with breast cancer were diagnosed as having initial bone metastasis. The follow-up period was from January 2010 to December 2014.

We defined patients' related variables including age at diagnosis (18-40, 41-60, and 61-80 years), sex (female and male), marital status (married, unmarried/divorced, and unknown), race (white, black, other [including American Indian/Alaska (AK) Native, Asian/Pacific Islander], and unknown), and Hispanic origin (yes and no). Cancer-related variables included tumor grade (grade I, grade II, grade III, and unknown), laterality (right, left, and unknown), primary tumor (T) stage (T1, T2, T3, T4, and unknown), regional lymph node stage (N0, N1, N2, N3, and unknown), and molecular subtype of breast cancer (HR+/HER2-, HR+/ HER2+, HR-/HER2+, triple-negative breast cancer [TNBC], and unknown). Information of local surgery was defined as surgery and no surgery, and metastasis status was categorized as bone metastasis only, multiple/other metastasis, no and unknown).

We calculated incidence of bone metastasis as the number of patients with bone metastasis at initial diagnosis divided by the number of patients in the entire cohort (bone metastasis in the entire cohort) or patients with $\mathrm{MBC}$ at initial diagnosis (bone metastasis in the initial MBC cohort).

\section{Statistical methods}

Rates of overall survival (OS) and cancer-specific survival (CSS) were calculated in the entire cohort and in patients with MBC subdivided based on metastasis location (bone, brain, liver, and lung). Univariate logistic analysis was used to assess significant characteristics correlated with the initial bone metastasis. Then, the significant factors $(P<0.05)$ were included in the multivariate logistic analysis to find independently the prognostic variables for the initial bone metastasis in the whole cohort. Univariate and multivariate Cox regression models were used to analyze the association of OS with clinical variables. Survival analysis was performed by Kaplan-Meier method and log-rank test.

All data was obtained using SEER*Stat Software version 8.3.4 (https://seer.cancer.gov/seerstat/). Statistical analyses were performed by SPSS statistical software version 22 . All $P$ values were two-sided, and $P \leq 0.05$ was considered significant.

\section{Ethical approval}

Our study complied with the 1964 Helsinki Declaration and its later amendments or comparable ethical standards.

\section{Results \\ Patients' characteristics and the bone metastasis pattern}

Exactly 245,707 patients were diagnosed with invasive breast cancer between 2010 and 2013; 3.6\% of the entire cohort was diagnosed with bone metastasis at the initial diagnosis, accounting for $62.5 \%$ of patients with initial MBC (Table 1 ). Also, $57.6 \%, 12.9 \%, 5.1 \%$, and $8 \%$ of patients with initial bone metastasis had HR+/HER2-, HR+/HER2+, HR-/ 
Table I Incidence of breast cancer with initial bone metastasis by the molecular subtype

\begin{tabular}{|c|c|c|c|c|c|}
\hline \multirow{2}{*}{$\begin{array}{l}\text { Molecular } \\
\text { subtype }\end{array}$} & \multicolumn{3}{|l|}{ Number (\%) } & \multicolumn{2}{|c|}{ Incidence of bone metastasis, \% } \\
\hline & Entire cohort & Initial MBC & $\begin{array}{l}\text { Bone } \\
\text { metastasis }\end{array}$ & $\begin{array}{l}\text { In the entire } \\
\text { cohort }\end{array}$ & $\begin{array}{l}\text { Among MBC } \\
\text { patients }\end{array}$ \\
\hline HR+/HER2- & $164,630(67)$ & $7117(50)$ & $5128(57.6)$ & 3.1 & 72.1 \\
\hline HR+/HER2+ & $22,798(9.2)$ & $1805(12.7)$ & $1150(12.9)$ & 5 & 63.7 \\
\hline HR-/HER2+ & $10,009(4.1)$ & $988(6.9)$ & $452(5.1)$ & 4.5 & 45.7 \\
\hline TNBC & $25,965(10.6)$ & $1653(11.6)$ & $715(8)$ & 2.8 & 43.3 \\
\hline Unknown & $22,305(9.1)$ & $2683(18.8)$ & $1456(16.4)$ & 6.5 & 54.3 \\
\hline Total & $245,707(100)$ & $14,246(100)$ & $8901(100)$ & 3.6 & 62.5 \\
\hline
\end{tabular}

Abbreviations: HER2, human epidermal growth factor receptor 2; HR, hormone receptor; MBC, metastatic breast cancer; TNBC, triple-negative breast cancer.

HER2+, and TNBC subtypes of breast cancer. There was a higher proportion of HR+ breast cancer in the cohort with initial bone metastasis compared to those with initial MBC (70.5\% vs $62.7 \%$ ), while less patients with bone metastasis were diagnosed with $\mathrm{HR}$ - breast cancer compared to that in the MBC cohort (13.1\% vs $18.5 \%$ ). Median follow-up in the entire cohort and in patients with initial bone metastasis was 31 and 18 months, respectively.

In the entire cohort, patients of Hispanic origin (no vs yes: odds ratio $[\mathrm{OR}]=1.256,95 \% \mathrm{CI}=1.163-1.356)$ and of American Indian/AK Native or Asian/Pacific Islander (other) race (other vs white: $\mathrm{OR}=0.748,95 \% \mathrm{CI}=0.682-0.819$ ) were correlated with lower odds of having initial bone metastasis, and patients with advanced T stage ( $\mathrm{T} 2$ vs $\mathrm{T} 1: \mathrm{OR}=3.278,95 \%$ $\mathrm{CI}=3.035-3.540$; $\mathrm{T} 3$ vs $\mathrm{T} 1$ : $\mathrm{OR}=6.766,95 \% \mathrm{CI}=6.175-7.413$; T4 vs T1: OR=22.112, 95\% CI=20.310-24.073) and lymph node involvement $(\mathrm{N} 1$ vs N0: $\mathrm{OR}=2.765,95 \% \mathrm{CI}=2.605$ 2.934; N2 vs N0: OR $=2.238,95 \%$ CI $=2.050-2.443$; N3 vs N0: OR=3.564, 95\% CI=3.268-3.887) were correlated with significantly higher odds of developing initial bone metastasis. With regard to molecular subtype in the entire cohort of breast cancer, patients with HR+/HER2+ subtype were more likely to have initial bone metastasis (HR+/HER2+ vs HR+/HER2-: OR $=1.105,95 \% \mathrm{CI}=1.027-1.187$ ), while those with HR-/HER2- or TNBC were less likely to have initial bone metastasis compared to those with HR+/HER2- breast cancer (HR-/HER2+ vs HR+/HER2-: OR $=0.700,95 \%$ $\mathrm{CI}=0.628-0.780 ;$ TNBC vs HR+/HER2 $-: \mathrm{OR}=0.520,95 \%$ $\mathrm{CI}=0.476-0.567)$. Multivariate logistic analysis regarding the risk factor screening in the entire cohort or MBC cohort is listed in Table 2.

\section{Survival of the initial bone metastasis breast cancer}

The 5-year survival rate based on OS and CSS was $23.7 \%$ and $35.4 \%$ in the initial MBC, respectively (Figure 1A, B).
Patients with initial bone metastasis (5-year survival rate for $\mathrm{OS}=22.8 \%$; 5-year survival rate for $\mathrm{CSS}=33.6 \%$ ) had a much better prognosis than those with initial brain ( 5 -year survival rate for $\mathrm{OS}=12 \% ; 5$-year survival rate for $\mathrm{CSS}=20.3 \%$ ), liver (5-year survival rate for OS=12.5\%; 5-year survival rate for $\mathrm{CSS}=19.3 \%$ ), or lung metastasis (5-year survival rate for $\mathrm{OS}=16.8 \%$; 5-year survival rate for $\mathrm{CSS}=26.9 \%$ ). Among patients with initial bone metastasis, patients with only bone metastases had a significantly better survival compared to patients with multiple metastases (bone vs multiple: median survival $=37$ vs 21 months, $P<0.001$; Figure $2 \mathrm{~A}$ ). With regard to the molecular subtype, we discovered that median survival of bone metastasis breast cancer was the shortest (10 months) in patients with TNBC and was the longest (41 months) in those with HR+/HER2+ subtype (Figure 2B). In primary bone metastasis breast cancer, local surgery could prominently prolong the survival compared to those with no surgery (surgery vs no surgery: median survival=43 vs 25 months, $P<0.001$; Figure 2C).

Multivariate Cox regression model showed that patients of black race (black vs white: hazard ratio $=1.202,95 \%$ $\mathrm{CI}=1.113-1.298$ ), in T4 stage ( $\mathrm{T} 4$ vs T1: hazard ratio $=1.270$, 95\% CI=1.144-1.411), with multiple metastases (bone only vs multiple: hazard ratio $=0.602,95 \% \mathrm{CI}=0.568-0.638)$, and with TNBC (TNBC vs HR+/HER2-: hazard ratio $=2.577$, 95\% CI=2.346-2.830) were correlated with higher risk of mortality due to breast cancer with initial bone metastasis. Patients who had their primary tumors resected had a 0.57 times lower risk of mortality compared to patients who did not accept local surgery (surgery vs no surgery: hazard ratio $=0.570,95 \% \mathrm{CI}=0.528-0.615$ ). Significant results are presented in Table 3.

\section{Discussion}

Our study has firstly reported the incidence of bone metastasis at the initial diagnosis of breast cancer and has found that 
Table 2 Multivariate logistic regression for the presence of bone metastasis in patients with breast cancer

\begin{tabular}{|c|c|c|c|c|c|c|}
\hline \multirow[t]{2}{*}{ Characteristics } & \multicolumn{2}{|c|}{ Patients, no. (\%) } & \multicolumn{2}{|l|}{ In the entire cohort ${ }^{a}$} & \multicolumn{2}{|c|}{ Among initial MBC patients ${ }^{a}$} \\
\hline & $\begin{array}{l}\text { Entire cohort } \\
(n=245,707)\end{array}$ & $\begin{array}{l}\text { With bone } \\
\text { metastasis } \\
(n=8901)\end{array}$ & OR (95\% CI) & $P$-value & OR $(95 \% \mathrm{CI})$ & $P$-value \\
\hline \multicolumn{7}{|l|}{ Age, years } \\
\hline $18-40$ & $13,920(5.7)$ & $613(6.9)$ & I (Reference) & NA & I (Reference) & NA \\
\hline $4 I-60$ & $100,422(40.9)$ & $3534(39.7)$ & $0.977(0.889-1.073)$ & 0.629 & $0.924(0.794-1.075)$ & 0.306 \\
\hline $6 I-80$ & $106,504(43.3)$ & $3758(42.2)$ & $1.056(0.96 \mathrm{I}-\mathrm{I} .162)$ & 0.258 & $0.83 \mid(0.7 \mid 3-0.969)$ & 0.018 \\
\hline$>80$ & $24,861(10.1)$ & $996(11.2)$ & $0.798(0.7 \mathrm{II}-0.895)$ & $<0.001$ & $0.624(0.522-0.746)$ & $<0.001$ \\
\hline \multicolumn{7}{|l|}{ Sex } \\
\hline Female & $243,786(99.2)$ & $8800(98.9)$ & I (Reference) & NA & I (Reference) & NA \\
\hline Male & $1921(0.8)$ & $101(1.1)$ & $0.956(0.766-1.193)$ & 0.69 & $0.996(0.704-1.4 I I)$ & 0.984 \\
\hline \multicolumn{7}{|l|}{ Marital status } \\
\hline Married & $130,200(53)$ & $3778(42.5)$ & I (Reference) & NA & I (Reference) & NA \\
\hline Unmarried & $100,495(40.9)$ & $4631(52)$ & 1.285 (I.223-I.350) & $<0.001$ & $1.086(1.005-1.174)$ & 0.038 \\
\hline Unknown & $15,012(6.1)$ & $492(5.5)$ & $0.891(0.802-0.989)$ & 0.031 & $0.970(0.826-1.138)$ & 0.704 \\
\hline \multicolumn{7}{|l|}{ Race } \\
\hline White & $195,472(79.6)$ & $6914(77.7)$ & I (Reference) & NA & I (Reference) & NA \\
\hline Black & 27,193 (II.I) & $1353(15.2)$ & $0.980(0.915-1.048)$ & 0.548 & $0.749(0.678-0.827)$ & $<0.001$ \\
\hline Other ${ }^{\mathrm{b}}$ & $21,393(8.7)$ & $601(6.8)$ & $0.748(0.682-0.819)$ & $<0.001$ & $0.809(0.70 \mathrm{I}-0.933)$ & 0.004 \\
\hline Unknown & $1649(0.6)$ & $33(0.3)$ & $0.45 \mid(0.3 \mid 3-0.65 I)$ & $<0.001$ & $0.863(0.485-1.536)$ & 0.618 \\
\hline \multicolumn{7}{|l|}{ Hispanic origin } \\
\hline Yes & $26,247(10.7)$ & $919(10.3)$ & I (Reference) & NA & I (Reference) & NA \\
\hline No & $219,460(89.3)$ & $7982(89.7)$ & $1.256(1.163-1.356)$ & $<0.001$ & I.I85 (I.052-I.335) & 0.005 \\
\hline \multicolumn{7}{|l|}{ Tumor grade } \\
\hline Grade I & $51,978(21.2)$ & $620(7)$ & I (Reference) & NA & I (Reference) & NA \\
\hline Grade II & $100,106(40.7)$ & $3107(34.9)$ & $1.582(|.444-| .732)$ & $<0.001$ & I.I59 (0.98I-I.368) & 0.082 \\
\hline Grade III & $74,259(30.2)$ & $2793(31.4)$ & $1.34 \mid(1.218-1.476)$ & $<0.001$ & $0.694(0.588-0.820)$ & $<0.001$ \\
\hline Unknown & $19,364(7.9)$ & $2381(26.7)$ & $3.066(2.765-3.40 I)$ & $<0.00$ I & $0.957(0.806-1.137)$ & 0.62 \\
\hline \multicolumn{7}{|l|}{ Laterality } \\
\hline Right & I 19,979 (48.8) & $4 \mid 27(46.4)$ & I (Reference) & NA & I (Reference) & NA \\
\hline Left & $124,036(50.5)$ & $4292(48.2)$ & $0.998(0.953-1.046)$ & 0.946 & $0.985(0.914-1.061)$ & 0.69 \\
\hline Unknown & $1692(0.7)$ & $482(5.4)$ & 3.071 (2.638-3.577) & $<0.001$ & $1.188(0.992-1.422)$ & 0.061 \\
\hline \multicolumn{7}{|l|}{ T stage } \\
\hline $\mathrm{TI}$ & $139,529(56.8)$ & $1053(11.8)$ & I (Reference) & NA & I (Reference) & NA \\
\hline $\mathrm{T} 2$ & $69,406(28.2)$ & $2306(25.9)$ & $3.278(3.035-3.540)$ & $<0.001$ & $1.098(0.964-1.250)$ & 0.16 \\
\hline T3 & $|4,34|(5.8)$ & $1166(13.1)$ & $6.766(6.175-7.413)$ & $<0.001$ & 1.087 (0.937-I.262) & $0.27 I$ \\
\hline $\mathrm{T} 4$ & $10,447(4.3)$ & $2519(28.3)$ & $22.112(20.310-24.073)$ & $<0.001$ & I.I83 (I.038-I.349) & 0.012 \\
\hline Unknown & II,984 (4.9) & $1857(20.9)$ & I2.827 (II.632-14.|45) & $<0.001$ & $1.050(0.908-1.214)$ & 0.512 \\
\hline \multicolumn{7}{|l|}{$\mathrm{N}$ stage } \\
\hline No & $163,122(66.4)$ & $2190(24.6)$ & I (Reference) & NA & I (Reference) & NA \\
\hline NI & $54,522(22.2)$ & $3569(40.1)$ & $2.765(2.605-2.934)$ & $<0.001$ & $1.132(1.027-1.249)$ & 0.013 \\
\hline N2 & $12,630(5.2)$ & $899(10.1)$ & $2.238(2.050-2.443)$ & $<0.001$ & $0.995(0.865-1.144)$ & $0.94 I$ \\
\hline N3 & $8210(3.3)$ & $1078(12.1)$ & $3.564(3.268-3.887)$ & $<0.001$ & $0.862(0.759-0.980)$ & 0.024 \\
\hline Unknown & $7223(2.9)$ & $1165(13.1)$ & $5.070(4.593-5.596)$ & $<0.001$ & $0.883(0.777-1.004)$ & 0.057 \\
\hline \multicolumn{7}{|l|}{ Subtype } \\
\hline HR+/HER2- & $164,630(67)$ & $5128(57.6)$ & I (Reference) & NA & I (Reference) & NA \\
\hline HR+/HER2+ & $22,798(9.3)$ & $1150(12.9)$ & I. 105 (I.027-I.I87) & 0.007 & $0.71 I(0.634-0.797)$ & $<0.001$ \\
\hline HR-/HER2+ & $10,009(4.1)$ & $452(5.1)$ & $0.700(0.628-0.780)$ & $<0.001$ & $0.354(0.307-0.408)$ & $<0.001$ \\
\hline TNBC & $25,965(10.5)$ & $715(8)$ & $0.520(0.476-0.567)$ & $<0.001$ & $0.340(0.302-0.382)$ & $<0.001$ \\
\hline Unknown & $22,305(9.1)$ & $1456(16.4)$ & $0.825(0.763-0.892)$ & $<0.001$ & $0.543(0.487-0.604)$ & $<0.001$ \\
\hline
\end{tabular}

Notes: aPatients with unknown information of bone metastasis were excluded from the entire cohort and the MBC cohort in the logistic model ( $n=5064$ and $n=446$; respectively). ${ }^{b}$ Other including American Indian/Alaska Native, Asian/Pacific Islander.

Abbreviations: HER2, human epidermal growth factor receptor 2; HR, hormone receptor; MBC, metastatic breast cancer; OR, odds ratio; TNBC, triple-negative breast cancer; NA, not available. 

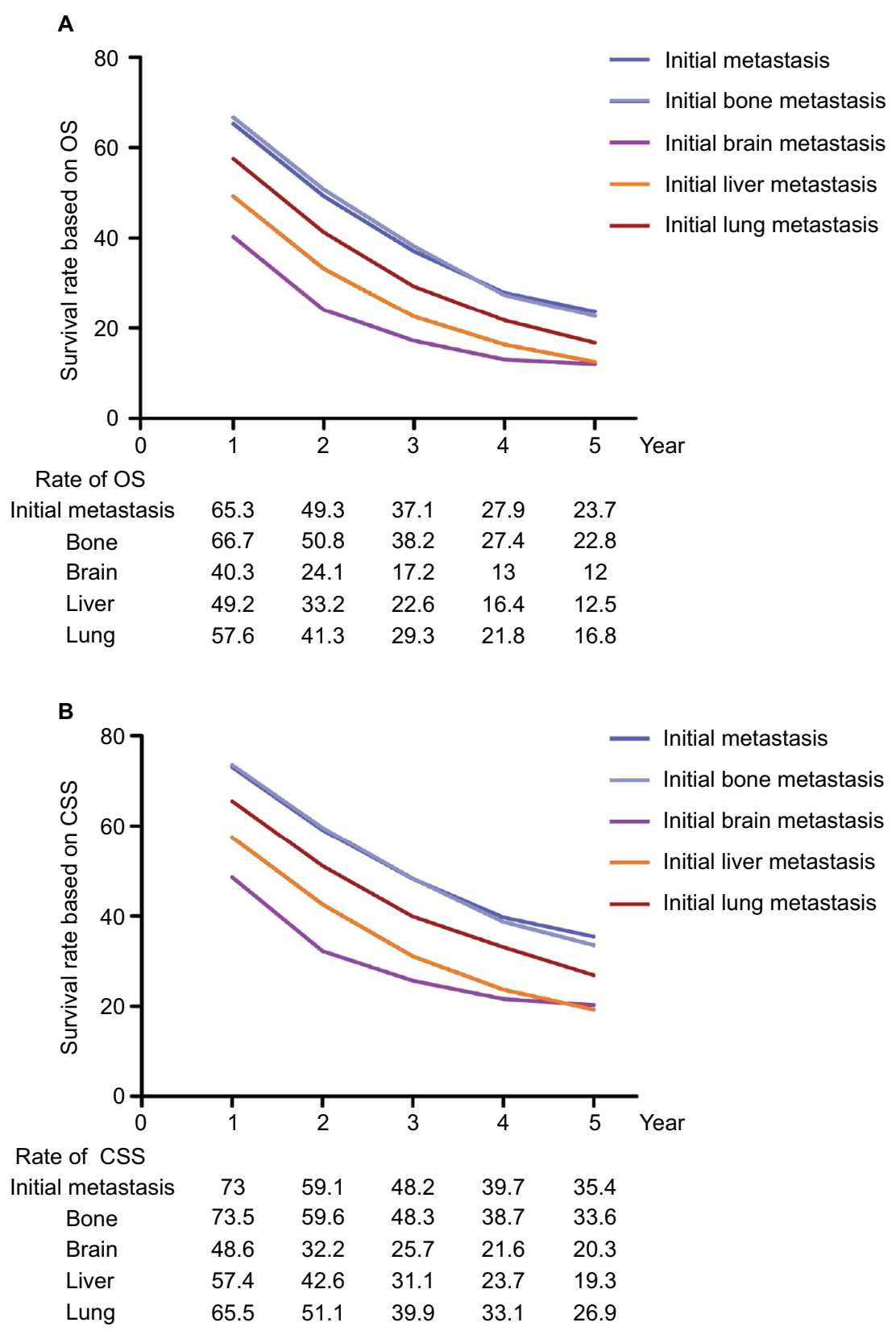

Figure I Survival rate based on (A) OS and (B) breast CSS in patients with initial metastatic breast cancer. Abbreviations: CSS, cancer-specific survival; OS, overall survival.

HR+ status, white race, young age (18-40 years), advanced T stage, and higher tumor grade are the risk factors of the initial bone metastasis. Further, we found that patients with initial bone metastasis had a better survival compared to those with initial brain, liver, or lung metastasis. Patients of old age (>40), black race, higher tumor grade, T4 stage, and TNBC were correlated with higher mortality risk, while those who underwent local surgery were associated with lower mortality risk. As our study is based on SEER database with $30 \%$ coverage of the USA population, bone metastasis incidence and survival estimates that we have reported are highly representative of the general population.

Bone is one of the most susceptible sites for cancer metastasis, especially in breast cancer. ${ }^{16}$ Our study found that $62.5 \%$ of patients with initial MBC were diagnosed with bone metastasis, which was consistent with the previous reports. ${ }^{17}$ Several factors were suggested to be responsible for bone metastasis. As metastasis through blood plays a major role in distant metastasis in breast cancer, the rich blood flow in the bone marrow and the stream of blood from the 
A

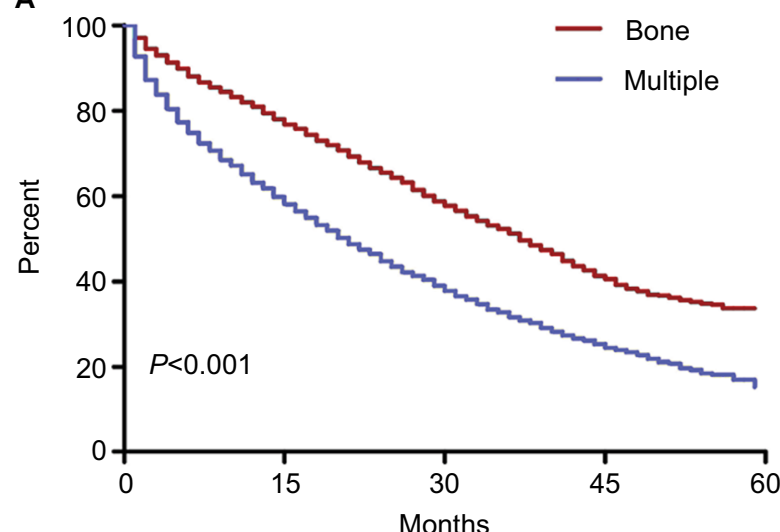

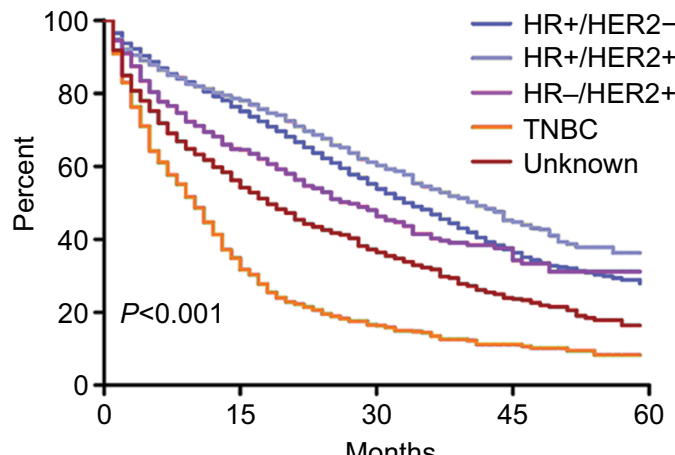

Number at risk $\begin{array}{lllll}\text { HR+/HER2-5128 } & 3454 & 1589 & 520 & 0\end{array}$ HR+/HER2+ $1150 \quad 792 \quad 355 \quad 125 \quad 0$ HR-/HER2+ $452 \quad 250 \quad 107 \quad 45 \quad 0$ $\begin{array}{llllll}\text { TNBC } & 715 & 214 & 66 & 24\end{array}$

276

Number at risk

Bone $\quad 4756 \quad 3290$

Multiple $\quad 4145 \quad 2026$

$\begin{array}{ll}1561 & 535 \\ 832 & 265\end{array}$

Unknown 1456

C

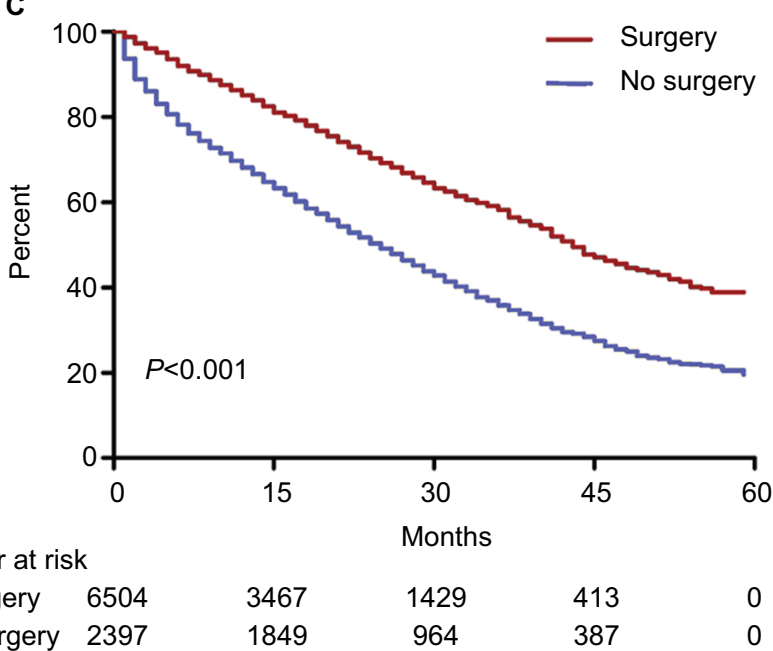

Figure 2 Survival analysis among patients with initial bone metastasis.

Notes: (A) Patients were stratified as bone metastasis only and multiple metastasis (bone vs multiple: median survival $=37$ vs $2 \mathrm{I}$ months, $P<0.00 \mathrm{I}$ ). (B) Patients were stratified as $\mathrm{HR}+/ \mathrm{HER} 2-$ (median survival=33 months), HR+/HER2+ (median survival=4l months), HR-/HER2+ (median survival=27 months), TNBC (median survival=I0 months), and unknown (median survival=18 months) $(P<0.00 \mathrm{I})$. (C) Patients were stratified according to whether they underwent local surgery or not (surgery vs no surgery: median survival $=43$ vs 25 months, $P<0.001$ ).

Abbreviations: HER2, human epidermal growth factor receptor 2; HR, hormone receptor; TNBC, triple-negative breast cancer.

breast to the skeleton via the vertebral-venous plexus would significantly increase the risk of cancer metastasis to bone. ${ }^{18}$ Otherwise, bone is suggested to be a large repository of growth-stimulating factors including fibroblast growth factors, platelet-derived growth factors, and bone morphogenetic proteins. These factors, released and activated in bone, could stimulate growth of tumor cells and act as a fertile ground for metastasis formation. ${ }^{19,20}$ Although bone metastasis is commonly seen in $\mathrm{MBC}$, the preferential metastasis sites of breast cancer were reported to be different based on HR status and HER2. ${ }^{21} \mathrm{HR}+$ or HER2- breast cancers are more likely to have skeletal involvement among patients with breast cancer recurrence. ${ }^{22}$ Further, our results showed a similar pattern of cancer metastasis among patients with initial MBC as the HR+ status (HR+/HER2- and HR+/HER2+) was significantly correlated with initial bone metastasis and most $(57.6 \%)$ of the patients with initial bone metastasis had a positive expression of HR. The mechanism regarding the propensity of bone metastasis for HR+ breast cancer remains unknown; however, some studies pointed out that this phenomenon may be associated with tumor dormancy. ${ }^{22-24}$ Studies suggested that dissemination of breast cancer cells takes place long before the detection of cancer metastasis and most of these disseminated cancer cells die while part of them might survive and become dormant in bone marrow. ${ }^{24,25}$ The dormant cancer cells with positive expression of HR, 
Table 3 Univariate and multivariate Cox regression for overall survival among patients with initial bone metastasis

\begin{tabular}{|c|c|c|c|c|}
\hline \multirow[t]{2}{*}{ Variate } & \multicolumn{2}{|l|}{ Univariate } & \multicolumn{2}{|l|}{ Multivariate } \\
\hline & Hazard ratio $(95 \% \mathrm{Cl})$ & $P$-value & Hazard ratio $(95 \% \mathrm{Cl})$ & $P$-value \\
\hline Age, years & & $<0.001$ & & $<0.001$ \\
\hline $18-40$ & I (Reference) & NA & I (Reference) & NA \\
\hline $41-60$ & $1.391(1.217-1.590)$ & $<0.001$ & $1.362(1.190-1.558)$ & $<0.001$ \\
\hline $6 I-80$ & $1.839(1.611-2.098)$ & $<0.001$ & 1.747 (1.528-1.999) & $<0.001$ \\
\hline$>80$ & $3.032(2.625-3.502)$ & $<0.001$ & $2.698(2.325-3.130)$ & $<0.001$ \\
\hline Sex (male vs female) & $0.968(0.740-1.265)$ & 0.811 & $0.9996(0.760-1.304)$ & 0.975 \\
\hline Marital status & & $<0.001$ & & $<0.001$ \\
\hline Married & I (Reference) & NA & I (Reference) & NA \\
\hline Unmarried & $1.468(1.384-1.556)$ & $<0.001$ & $1.266(1.191-1.345)$ & $<0.001$ \\
\hline Unknown & 1.285 (I.133-1.457) & $<0.001$ & $1.166(1.027-1.324)$ & 0.018 \\
\hline Race & & $<0.001$ & & $<0.001$ \\
\hline White & I (Reference) & NA & I (Reference) & NA \\
\hline Black & $1.312(1.219-1.412)$ & $<0.001$ & $1.202(1.113-1.298)$ & $<0.001$ \\
\hline Other ${ }^{a}$ & $0.915(0.815-1.027)$ & 0.133 & $0.935(0.832-1.051)$ & 0.259 \\
\hline Unknown & $0.524(0.272-1.007)$ & 0.053 & $0.452(0.234-0.870)$ & 0.17 \\
\hline Hispanic origin (yes vs no) & $0.854(0.777-0.938)$ & 0.001 & $0.963(0.875-1.061)$ & 0.446 \\
\hline Tumor grade & & $<0.001$ & & $<0.001$ \\
\hline Grade I & I (Reference) & NA & I (Reference) & NA \\
\hline Grade II & I.252 (I.099-I.425) & 0.001 & $1.180(1.036-1.345)$ & 0.013 \\
\hline Grade III & $1.760(1.547-2.002)$ & $<0.001$ & $1.58 \mid(1.383-1.807)$ & $<0.001$ \\
\hline Unknown & $2.054(1.804-2.339)$ & $<0.001$ & $1.393(1.217-1.595)$ & $<0.001$ \\
\hline Laterality & & $<0.001$ & & $<0.001$ \\
\hline Right & I (Reference) & NA & I (Reference) & NA \\
\hline Left & $1.037(0.979-1.098)$ & 0.215 & $1.049(0.991-1.111)$ & 0.102 \\
\hline Unknown & $1.388(1.235-1.561)$ & $<0.001$ & $0.796(0.698-0.907)$ & 0.001 \\
\hline T stage & & $<0.001$ & & $<0.001$ \\
\hline TI & I (Reference) & NA & I (Reference) & NA \\
\hline $\mathrm{T} 2$ & $1.015(0.913-1.129)$ & 0.78 & I.052 (0.945-I.I7I) & 0.352 \\
\hline $\mathrm{T} 3$ & $1.100(0.977-1.239)$ & 0.117 & $1.102(0.976-1.245)$ & 0.115 \\
\hline $\mathrm{T} 4$ & $1.550(1.400-1.715)$ & $<0.001$ & $1.270(1.144-1.411)$ & $<0.001$ \\
\hline Unknown & $1.813(1.633-2.013)$ & $<0.001$ & $1.321(1.180-1.480)$ & $<0.001$ \\
\hline$N$ stage & & $<0.001$ & & 0.096 \\
\hline No & I (Reference) & NA & I (Reference) & NA \\
\hline NI & $0.970(0.903-1.042)$ & 0.409 & $0.935(0.868-1.007)$ & 0.075 \\
\hline N2 & $0.870(0.782-0.967)$ & 0.01 & $0.990(0.886-1.106)$ & 0.856 \\
\hline N3 & $0.894(0.809-0.987)$ & 0.027 & $1.005(0.905-1.115)$ & 0.931 \\
\hline Unknown & $1.480(1.354-1.618)$ & $<0.001$ & $\mathrm{I} .048(0.954-\mathrm{I} .152)$ & 0.324 \\
\hline Metastasis status (bone only vs multiple) & $0.538(0.509-0.569)$ & $<0.001$ & $0.602(0.568-0.638)$ & $<0.001$ \\
\hline Subtype & & $<0.001$ & & $<0.001$ \\
\hline HR+/HER2- & I (Reference) & NA & I (Reference) & NA \\
\hline HR+/HER2+ & $0.85 \mathrm{I}(0.774-0.937)$ & 0.001 & $0.80 I(0.726-0.883)$ & $<0.001$ \\
\hline HR-/HER2+ & $1.252(1.100-1.426)$ & 0.001 & $1.128(0.988-1.289)$ & 0.076 \\
\hline TNBC & $2.777(2.539-3.038)$ & $<0.001$ & $2.577(2.346-2.830)$ & $<0.001$ \\
\hline Unknown & $2.014(1.874-2.164)$ & $<0.001$ & $1.605(1.485-1.735)$ & $<0.001$ \\
\hline Surgery (surgery vs no surgery) & $0.485(0.453-0.520)$ & $<0.001$ & $0.570(0.528-0.615)$ & $<0.001$ \\
\hline
\end{tabular}

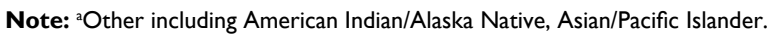

Abbreviations: HER2, human epidermal growth factor receptor 2; HR, hormone receptor; ORs, odds ratios; TNBC, triple-negative breast cancer; NA, not available.

which are hormone responsive, could be reactivated by steroid hormone and they subsequently develop metastasis disease in bone. ${ }^{22}$

Next, we assessed the survival rates depending on OS and CSS among patients with MBC and observed that outcome of patients with initial bone metastasis was better than those with initial brain, liver, or lung metastasis. The consequences of cancer metastasis are often devastating as the cancer cells would cause tissue damage and destruction of organs with metastatic diseases. ${ }^{26}$ In breast cancer, bone metastasis is predominantly characterized as osteolytic, which causes severe pain, pathologic fracture, or nerve 
compression, and is considered to be less deadly compared to metastasis of brain, liver, and lung. ${ }^{27,28}$ As the cancer cells have spread widely in MBC patients, chemotherapy and targeted therapy (endocrine therapy and anti-HER2 therapy) become optimal options for cancer treatment. Patients with $\mathrm{HR}+$ breast cancer, which is highly responsive to targeted therapy (endocrine therapy), as well as those with HER2+ breast cancer, which is responsive to anti-HER2 therapy, could achieve tumor remission and improved survival with endocrine therapy. ${ }^{29,30}$ Thus, the better outcome in patients with initial bone metastasis might be attributed to the higher proportion of patients with $\mathrm{HR}+$ diseases. Consistently, in breast cancer with initial bone metastasis, we observed a significantly lower mortality risk for patients with $\mathrm{HR}+$ or HER2+ breast cancer compared to those with TNBC, which was unresponsive to targeted therapy.

Since organ destruction resulting from cancer metastasis is the major cause of death in MBC, local surgery to primary tumor was thought to be invalid to improve cancer survival. ${ }^{31}$ Interestingly, our study showed that surgical removal of the primary tumor might improve cancer survival in newly diagnosed breast cancer with bone metastasis. Consistently, both retrospective studies and randomized trials have indicated that local surgery may improve cancer survival by lowering the tumor burden in initial MBC. ${ }^{32-34} \mathrm{~A}$ study using a cancer transplantation model in mice suggested that local surgery of the primary tumor improves survival by both reducing the tumor burden and enhancing sensitivity to chemotherapy. ${ }^{35}$ Meanwhile, the results of experimental and clinical studies were opposed the survival benefit of local surgery based on the theory that surgical removal of the primary tumor would prompt growth of metastasis by increasing the adhesion of circulating tumor cells to the vascular endothelium of target organs and inducing inflammatory cascade. ${ }^{31,36}$ Thus, the survival benefit of local surgery remains unclear in initial MBC and more welldesigned studies are required to guide cancer therapy.

There are some limitations in our study. As our study is retrospective, selection bias and missing data are inevitable. Details of systemic therapy including anti-HER2 therapy, endocrine therapy, and chemotherapy are not available in our study, and the relevant biases may exist. Randomized and prospective studies with large patient cohort are required to identify the validity of surgery in initial MBC with bone metastasis.

\section{Conclusion}

Our study has reported the epidemiology of patients with bone metastasis in initial MBC based on a general population in the USA. Patients with bone metastasis had a superior prognosis compared to those with visceral/brain metastasis in initial MBC. Incidence and survival differences of initial bone metastasis were well described according to the different molecular subtypes in initial MBC. We also discovered that local surgery could significantly improve cancer survival, suggesting that patients with bone metastasis might consider local surgery in initial MBC.

\section{Availability of data and material}

The data of our study are freely provided by the SEER Research database (http://www.seer.cancer.gov).

\section{Author contributions}

$\mathrm{ZX}$ and $\mathrm{XW}$ designed the overall project. $\mathrm{ZX}$ and $\mathrm{XH}$ analyzed the data and wrote the manuscript. GD and XX collected and analyzed the data. XL and ZS performed the research. JW did the statistical analysis. All the authors (XW, ZX, GD, XH, JW, XL, XX, ZS) have read and approved the final manuscript. All authors contributed toward data analysis, drafting and revising the paper and agree to be accountable for all aspects of the work.

\section{Disclosure}

The authors report no conflicts of interest in this work.

\section{References}

1. Roodman GD. Mechanisms of bone metastasis. N Engl J Med. 2004; 350(16):1655-1664.

2. Dawood S, Broglio K, Ensor J, Hortobagyi GN, Giordano SH. Survival differences among women with de novo stage IV and relapsed breast cancer. Ann Oncol. 2010;21(11):2169-2174.

3. Yang Y, Ma Y, Sheng J, et al. A multicenter, retrospective epidemiologic survey of the clinical features and management of bone metastatic disease in China. Chin J Cancer. 2016;35:40.

4. Steinman RA, Brufsky AM, Oesterreich S. Zoledronic acid effectiveness against breast cancer metastases - a role for estrogen in the microenvironment? Breast Cancer Res. 2012;14(5):213.

5. Brufsky A, Mathew A. Bisphosphonates, bone, and breast cancer recurrence. Lancet. 2015;386(10001):1319-1320.

6. Coleman RE, Lipton A, Roodman GD, et al. Metastasis and bone loss: advancing treatment and prevention. Cancer Treat Rev. 2010;36(8): 615-620.

7. Cianfrocca M, Gradishar W. New molecular classifications of breast cancer. CA Cancer J Clin. 2009;59(5):303-313.

8. Amin MB, Greene FL, Edge SB, et al. The eighth edition AJCC cancer staging manual: continuing to build a bridge from a population-based to a more "personalized" approach to cancer staging. CA Cancer J Clin. 2017;67(2):93-99.

9. Smid M, Wang Y, Zhang Y, et al. Subtypes of breast cancer show preferential site of relapse. Cancer Res. 2008;68(9):3108-3114.

10. Tobin NP, Harrell JC, Lovrot J, et al; TEX Trialists Group. Molecular subtype and tumor characteristics of breast cancer metastases as assessed by gene expression significantly influence patient post-relapse survival. Ann Oncol. 2015;26(1):81-88.

11. Schroder J, Fietz T, Kohler A, et al; TMK-Group (Tumour Registry Breast Cancer). Treatment and pattern of bone metastases in 1094 patients with advanced breast cancer - Results from the prospective German Tumour Registry Breast Cancer cohort study. Eur J Cancer. 2017;79:139-148. 
12. Sihto H, Lundin J, Lundin M, et al. Breast cancer biological subtypes and protein expression predict for the preferential distant metastasis sites: a nationwide cohort study. Breast Cancer Res. 2011; 13(5):R87.

13. Delpech Y, Bashour SI, Lousquy R, et al. Clinical nomogram to predict bone-only metastasis in patients with early breast carcinoma. $\mathrm{Br} J$ Cancer. 2015;113(7):1003-1009.

14. Vaz-Luis I, Ottesen RA, Hughes ME, et al. Impact of hormone receptor status on patterns of recurrence and clinical outcomes among patients with human epidermal growth factor-2-positive breast cancer in the National Comprehensive Cancer Network: a prospective cohort study. Breast Cancer Res. 2012;14(5):R129.

15. Surveillance E, Results E. (SEER) Program Research Data (1973-2013), National Cancer Institute, DCCPS, Surveillance Research Program, Surveillance Systems Branch, released April 2016, based on the November 2015 submission. Available from: http://www.seer.cancer.gov. Accessed August 15, 2016

16. Yin JJ, Pollock CB, Kelly K. Mechanisms of cancer metastasis to the bone. Cell Res. 2005;15(1):57-62.

17. Ibrahim T, Mercatali L, Amadori D. A new emergency in oncology: bone metastases in breast cancer patients (Review). Oncol Lett. 2013;6(2):306-310.

18. Coleman RE. Clinical features of metastatic bone disease and risk of skeletal morbidity. Clin Cancer Res. 2006;12(20 Pt 2):6243s-6249s.

19. Xu J,Acharya S, Sahin O, et al. 14-3-3zeta turns TGF-beta's function from tumor suppressor to metastasis promoter in breast cancer by contextual changes of Smad partners from p53 to Gli2. Cancer Cell. 2015;27(2): 177-192.

20. Zhang XH, Jin X, Malladi S, et al. Selection of bone metastasis seeds by mesenchymal signals in the primary tumor stroma. Cell. 2013;154(5):1060-1073.

21. Hess KR, Esteva FJ. Effect of HER2 status on distant recurrence in early stage breast cancer. Breast Cancer Res Treat. 2013;137(2):449-455.

22. Zhang XH, Giuliano M, Trivedi MV, Schiff R, Osborne CK. Metastasis dormancy in estrogen receptor-positive breast cancer. Clin Cancer Res. 2013;19(23):6389-6397.

23. Gao H, Chakraborty G, Lee-Lim AP, et al. The BMP inhibitor Coco reactivates breast cancer cells at lung metastatic sites. Cell. 2012;150(4): $764-779$
24. Husemann Y, Geigl JB, Schubert F, et al. Systemic spread is an early step in breast cancer. Cancer Cell. 2008;13(1):58-68.

25. Lu X, Mu E, Wei Y, et al. VCAM-1 promotes osteolytic expansion of indolent bone micrometastasis of breast cancer by engaging alpha4beta1positive osteoclast progenitors. Cancer Cell. 2011;20(6):701-714.

26. Guise TA. Breast cancer bone metastases: it's all about the neighborhood. Cell. 2013;154(5):957-959.

27. Skeletal Complications of Malignancy. Proceedings of a symposium. Bethesda, Maryland, April 19-20, 1997. Cancer. 1997;80(8 Suppl): 1527-1701.

28. Hölzel D, Eckel R, Bauerfeind I, et al. Survival of de novo stage IV breast cancer patients over three decades. JCancer Res Clin Oncol. 2016;143(3): 509-519.

29. Swain SM, Baselga J, Kim SB, et al; CLEOPATRA Study Group. Pertuzumab, trastuzumab, and docetaxel in HER2-positive metastatic breast cancer. N Engl J Med. 2015;372(8):724-734.

30. Lee JY, Won HY, Park JH, et al. MEL-18 loss mediates estrogen receptor- $\alpha$ downregulation and hormone independence. J Clin Invest 2015;125(5):1801-1814.

31. Badwe R, Hawaldar R, Nair N, et al. Locoregional treatment versus no treatment of the primary tumour in metastatic breast cancer: an open-label randomised controlled trial. Lancet Oncol. 2015;16(13):1380-1388.

32. Rapiti E, Verkooijen HM, Vlastos G, et al. Complete excision of primary breast tumor improves survival of patients with metastatic breast cancer at diagnosis. J Clin Oncol. 2006;24(18):2743-2749.

33. Cady B, Nathan NR, Michaelson JS, Golshan M, Smith BL. Matched pair analyses of stage IV breast cancer with or without resection of primary breast site. Ann Surg Oncol. 2008;15(12):3384-3395.

34. Soran A, Ozbas S, Kelsey SF, Gulluoglu BM. Randomized trial comparing locoregional resection of primary tumor with no surgery in stage IV breast cancer at the presentation (Protocol MF07-01): a study of Turkish Federation of the National Societies for Breast Diseases. Breast J. 2009;15(4):399-403.

35. Rashid OM, Nagahashi M, Ramachandran S, et al. Resection of the primary tumor improves survival in metastatic breast cancer by reducing overall tumor burden. Surgery. 2013;153(6):771-778.

36. Al-Sahaf O, Wang JH, Browne TJ, Cotter TG, Redmond HP. Surgical injury enhances the expression of genes that mediate breast cancer metastasis to the lung. Ann Surg. 2010;252(6):1037-1043.
Cancer Management and Research

\section{Publish your work in this journal}

Cancer Management and Research is an international, peer-reviewed open access journal focusing on cancer research and the optimal use of preventative and integrated treatment interventions to achieve improved outcomes, enhanced survival and quality of life for the cancer patient. The manuscript management system is completely online and includes

\section{Dovepress}

a very quick and fair peer-review system, which is all easy to use. Visit $\mathrm{http}: / / \mathrm{www}$.dovepress.com/testimonials.php to read real quotes from published authors. 